\title{
Effect of Rhodopseudomonas palustris G5 on seedling growth and some physiological and biochemical characteristics of cucumber under cadmium stress
}

\author{
Honglian Ge*, Zhonghua Liu, Fuli Zhang \\ College of Life Science and Agronomy, Zhoukou Normal University, Zhoukou, 466001, China
}

\section{A B S T R A C T}

\begin{abstract}
At present, we investigated whether Rhodopseudomonas palustris G5 strain treatments diminished the damage on cucumber seedlings caused by cadmium (Cd) stress. Growth and physiological parameters of cucumber seedlings were determinated at laboratory after cotreating seedlings with Rhodopseudomonas palustris G5 strain and different concentrations of Cd (50, 100, 150, 200, 300 mg L-1). The results indicated that $\mathrm{Cd}$ stress significantly reduced shoot height, root length, total chlorophyll content, root activity, but increased malondialdehyde (MDA) content. In addition, lower concentrations of $\mathrm{Cd}$ stress increased soluble sugar and soluble protein contents, and improved the activities of superoxide dismutase (SOD; EC: 1.15.1.1) and peroxidase (POD; EC: 1.11.1.7), but higher concentrations of Cd decreased the soluble sugar and soluble protein contents, and inhibited SOD and POD activities. G5 strain application markedly reduced the toxic effects of $\mathrm{Cd}$ on cucumber seedlings. In sum, G5 strain treatment significantly alleviated damage on cucumber seedlings caused by $\mathrm{Cd}$, and increased shoot height, root length, total chlorophyll content, root activity, the contents of soluble sugar and soluble protein, as well as the activities of SOD and POD, but decreased MDA content compared with non- treating plants.
\end{abstract}

Keywords: Rhodopseudomonas palustris; Cadmium; Cucumber seedlings; Physiological parameters; Antioxidant enzymes

\section{INTRODUCTION}

Cadmium is one of environmentally toxic contaminants. Cadmium is taken up from the soil by plants, which means that it can potentially threaten human health via the food chain (Fargasova, 2001; Gill et al., 2011). Some studies have shown that $\mathrm{Cd}$ can adversely affect plant growth, photosynthesis, and some physiological parameters (ElBeltagi et al., 2010; Mishra et al., 2014; Xu et al., 2008). For example, Mishra et al. (2014) suggested that supplemental exposure to $\mathrm{Cd}$ could affect the plant metabolic status at higher doses, stunt growth, and cause chlorosis and necrosis in shoot cultures of ashwagandha. El-Beltagi et al. (2010) reported that $\mathrm{Cd}$ inhibited antioxidant enzyme activity, decreased water potential in radish. Cadmium stress promoted the generation of reactive oxygen species (ROS). Excessive accumulation of ROS induced lipid peroxidation, and then damage DNA, RNA, proteins, and membranes (Weckx et al., 1996). Under environmental stress, in order to resist ROS damage, plants formed protective mechanisms including enzymatic and non-enzymatic mechanisms (Mishra et al., 2014). However, when the stress level exceeded the tolerance threshold of the plant, ROS cannot be eliminated, leading to decreasing of antioxidant enzyme activities and growth inhibition (Li et al., 2008). Therefore, the development of strategies to mitigate damage caused by $\mathrm{Cd}$ has received considerable attention. Popova et al. (2009) reported that salicylic acid treatment attenuated cadmium damage on pea seedlings. Li et al. (2013) showed that applying silicon and cerium to soils enhanced lettuce resistance to $\mathrm{Cd}$ stress.

Photosynthetic bacteria, which are common microorganisms in the natural environment, can produce 5-aminolevulinic acid (ALA), indole acetic acid (IAA), porphyrin compounds, and antiviral factors (Nunkaew et al., 2014; Sasaki et al., 2005). These substances can enhance the activity of plant cell, which improves photosynthesis efficiency and promotes the production of antioxidant enzymes that enhance plant resistance to stress. Some studies have

\footnotetext{
${ }^{*}$ Corresponding author:

Honglian Ge, College of Life Science and Agronomy, Zhoukou Normal University, Zhoukou, 466001, China.

E-mail: gehonglian2003@126.com
} 
shown that photosynthetic bacteria producing ALA can regulate plant metabolism and prevent the oxidative damage in plant cells (Nunkaew et al., 2014; Xu et al., 2016). Nevertheless, whether G5 strain can lessen the toxicity of $\mathrm{Cd}$ is still elusive. Therefore, we determined the alleviation effect of Rhodopseudomonas palustris G5 strain on $\mathrm{Cd}$ damage in cucumber and analyzed mechanisms underlying detoxification of G5 strain by measuring the growth and physiological indexes of cucumber seedlings under the stress of $\mathrm{Cd}$. Thus, this study will contribute to isolate the G5 strain and further apply it in practice.

\section{MATERIALS AND METHODS}

\section{Microbial inoculants}

Rhodopseudomonas palustris G5 strain, which could produce ALA, was isolated by our laboratory. Under anaerobic conditions, G5 strain was cultured in improved RCVBN medium for 7 days at $28^{\circ} \mathrm{C}$, with a PPF of $100 \mu \mathrm{moL} \mathrm{m} \mathrm{s}^{-1}$ light (Xu et al., 2016). The cells of G5 strain were collected by centrifugation at $5,000 \mathrm{r} \mathrm{min}{ }^{-1}$ for $15 \mathrm{~min}$. In sterile water, the pellets were resuspended to reach a final concentration of $10^{9} \mathrm{CFU} \mathrm{mL} \mathrm{m}^{-1}$.

\section{Experimental design}

The cucumber seeds were cleansed with $70 \%$ ethanol for surface sterilization for $2 \mathrm{~min}$, then further sterilized with $0.05 \%$ sodium hypochlorite for $10 \mathrm{~min}$. Thirdly, the seeds were washed in sterile water. Finally, the seeds allowed to germinate on water-soaked sterile paper in Petri dishes at $28^{\circ} \mathrm{C}$ in the dark for 4 days.

$\mathrm{Cd}\left(\mathrm{NO}_{3}\right)_{2} 4 \mathrm{H}_{2} \mathrm{O}$ was dissolved in Hoagland's nutrient solution to obtain $\mathrm{Cd}$ concentrations of $0,50,100,150$, 200 and $300 \mathrm{mg} \mathrm{L}^{-1}$. After that, Hoagland's nutrient solution that contained different concentrations of $\mathrm{Cd}$ was placed into plastic trays of $5 \mathrm{~cm}$ high, $24 \mathrm{~cm}$ wide and $37 \mathrm{~cm}$ long, respectively. The seedlings were randomly divided into 2 groups, A and B, and every group was divided into five subgroups. Group A seedlings were treated in Hoagland's nutrient solution that contained different concentrations of Cd. Group B seedlings were treated in a similar way, except that $10 \mathrm{~mL}$ of Rhodopsendomonas palustris G5 strain was added. The nutrient solution was renewed two times weekly. Each treatment had 3 repeated samples and each one contained 10 plastic trays. Cucumber seedlings without Cd and G5 strain treatments were used as controls. The seedlings were put into climate chamber which was operated with an illumination time of $12 \mathrm{~h} /$ day and relative humidity of $70 \%$ at diurnal temperature (day $/$ night) $30 / 23^{\circ} \mathrm{C}$. After 13 days of treatment, the physiological and biochemical indexes of the leaves were determined with leaves at the same position on each stem.

\section{Measurement of growth parameters}

At 13 days after G5 strain and Cd treatment, the shoot heights and root lengths were measured for G5 strain and every Cd treatment according to Lutts et al. (1996).

\section{Measurement of physiological and biochemical indexes of cucumber seedlings}

The activities of SOD and POD were measured according to the methods of Wu and Von Tiedemann (2002). The contents of chlorophyll and malondialdehyde (MDA) was assayed as described by Hegedüs et al. (2001). Soluble sugar content was analyzed according to the methods of ZarcoTejada et al. (2005). Soluble protein content was determined using the methods of Bradford (1976). Root activity was determined according to the methods of Kerley (2000).

\section{Data analysis}

All date presented here were means of three replicates. The mean and the standard deviation $( \pm \mathrm{SD})$ were calculated using Microsoft Excel 2007. The date were analyzed at significant levels of $P<0.05$ using one way ANOVA.

\section{RESULTS AND DISCUSSION}

The effects of G5 strain and Cd treatment on shoot height and root length of cucumber seedlings

At present, $\mathrm{Cd}$ stress significantly inhibited the growth of cucumber $(P<0.05)$ (Table 1$)$. And $300 \mathrm{mg} \mathrm{L}^{-1} \mathrm{Cd}$ resulted in the most obvious reduction in shoot height and root length (decreased by $29.24 \%$, and $14.01 \%$ compared to the control, respectively). All G5 strain treatment diminished inhibition on the shoot heights and root lengths of cucumber seedlings caused by $\mathrm{Cd}$ stress $(P<0.05)$. The greatest significant improvement in shoot height occurred when cucumber seedlings were treated with G5 and $200 \mathrm{mg}$ $\mathrm{L}^{-1} \mathrm{Cd}$ (increased by $19.00 \%$ compared to that of the seedlings under $200 \mathrm{mg} \mathrm{L}^{-1} \mathrm{Cd}$ stress) $(P<0.05)$ (Table 1$)$, whereas the largest increase of $14.51 \%$ in root length was observed at the seedlings treated with G5 strain and $300 \mathrm{mg}$ $\mathrm{L}^{-1} \mathrm{Cd}$ treatment $(P<0.05)$. These results showed that $\mathrm{G} 5$ strain had the ability to enhance cucumber resistance to $\mathrm{Cd}$ stress. Current results were in agreement with the findings of Xu et al. (2016), finding that Rhodopsendomonas palustris could increase plant biomass under abiotic stress.

The effects of G5 strain and Cd treatment on total chlorophyll content and root activity in cucumber seedlings

Chlorophyll is a key indicator of damage inflicted on plant by heavy metals (Wang et al., 2006). Heavy metals stresses often decreased the total chlorophyll content. Current studies showed that 50 to $300 \mathrm{mg} \mathrm{L}^{-1} \mathrm{Cd}$ significantly decreased the total chlorophyll content in cucumber leaves $(P<0.05)$ (Table 2). The largest fall in total chlorophyll 
Ge, et al.: Effect of R. palustris $\mathbf{G 5}$ on cucumbe

Table 1: Effects of G5 strain and Cd treatment on shoot height and root length of cucumber seedlings

\begin{tabular}{|c|c|c|c|c|}
\hline \multirow[t]{2}{*}{ Concentration (mg L $\left.{ }^{-1} \mathrm{Cd}\right)$} & \multicolumn{2}{|c|}{ Shoot height (cm) } & \multicolumn{2}{|c|}{ Root length (cm) } \\
\hline & $-G 5$ & +G5 & $-\mathrm{G5}$ & +G5 \\
\hline 0 & $13.92 \pm 0.23^{a}$ & $15.26 \pm 0.22^{a}$ & $5.21 \pm 0.03^{a}$ & $5.94 \pm 0.03^{a}$ \\
\hline 50 & $12.37 \pm 0.36^{b}$ & $13.89 \pm 0.28^{b}$ & $5.07 \pm 0.09^{b}$ & $5.76 \pm 0.07^{a}$ \\
\hline 100 & $11.86 \pm 0.21^{c}$ & $13.27 \pm 0.17^{c}$ & $4.94 \pm 0.08^{c}$ & $5.33 \pm 0.05^{b}$ \\
\hline 150 & $10.77 \pm 0.15^{d}$ & $12.51 \pm 0.25^{d}$ & $4.82 \pm 0.01^{d}$ & $5.43 \pm 0.02^{b}$ \\
\hline 200 & $10.21 \pm 0.20^{e}$ & $12.15 \pm 0.16^{d}$ & $4.67 \pm 0.07^{\mathrm{e}}$ & $5.21 \pm 0.06^{\mathrm{bc}}$ \\
\hline 300 & $9.85 \pm 0.13^{e}$ & $11.52 \pm 0.19^{\mathrm{e}}$ & $4.48 \pm 0.05^{f}$ & $5.13 \pm 0.06^{c}$ \\
\hline
\end{tabular}

Data are means $\pm \mathrm{SD}$, different lowercase letters in the same column indicate significant differences at $P<0.05$

Table 2: Effects of G5 strain and Cd treatment on total chlorophyll content and root activity in cucumber seedling

\begin{tabular}{|c|c|c|c|c|}
\hline \multirow[t]{2}{*}{ Concentration (mg L ${ }^{-1} \mathrm{Cd}$ ) } & \multicolumn{2}{|c|}{ Chlorophyll content (mg g $\left.{ }^{-1} \mathrm{FW}\right)$} & \multicolumn{2}{|c|}{ Root activity $\left(\mu \mathrm{g} \mathrm{g}{ }^{-1} \mathrm{~h}^{-1}\right)$} \\
\hline & $-\mathrm{G5}$ & +G5 & $-\mathrm{G5}$ & +G5 \\
\hline 0 & $3.65 \pm 0.70^{a}$ & $3.9 \pm 0.26^{a}$ & $351.43 \pm 18.84^{a}$ & $393.82 \pm 11.82^{a}$ \\
\hline 50 & $2.15 \pm 0.2^{b}$ & $2.93 \pm 0.13^{b}$ & $295.27 \pm 15.58^{b}$ & $368.54 \pm 14.62^{b}$ \\
\hline 100 & $1.69 \pm 0.21^{b c}$ & $2.23 \pm 0.19^{c}$ & $256.62 \pm 11.83^{c}$ & $328.17 \pm 13.53^{c}$ \\
\hline 150 & $1.35 \pm 0.30^{c}$ & $1.94 \pm 0.36^{\mathrm{cd}}$ & $217.90 \pm 12.27^{d}$ & $312.68 \pm 11.58^{\mathrm{cd}}$ \\
\hline 200 & $1.21 \pm 0.13^{c}$ & $1.62 \pm 0.18^{d}$ & $156.31 \pm 9.75^{e}$ & $291.65 \pm 10.90^{\text {de }}$ \\
\hline 300 & $1.02 \pm 0.4^{c}$ & $1.49 \pm 0.13^{d}$ & $126.84 \pm 11.47^{f}$ & $270.19 \pm 15.56^{e}$ \\
\hline
\end{tabular}

Data are means $\pm \mathrm{SD}$, different lowercase letters in the same column indicate significant differences at $P<0.05$

content occurred under $300 \mathrm{mg} \mathrm{L}^{-1} \mathrm{Cd}$ treatment (decreased by $72.05 \%$ compared to the control). The decrease of total chlorophyll content could be caused by the disturbance of light-harvesting complex formation, inhibition of chlorophyll biosynthesis and photooxidation breakdown of free chlorophyll (Pružinská et al., 2003). G5 strain treatment significantly increased total chlorophyll content of cucumber seedlings exposed to different concentrations of $\mathrm{Cd}(P<0.05)$. Current results agree with findings of Nunkaew et al. (2014), reporting that photosynthetic bacteria producing ALA could increase the chlorophyll content of plant under $\mathrm{NaCl}$ stress. In addition, Akram et al. (2013) demonstrated that ALA was a potential plant growth regulator and was considered as a precursor for chlorophyll biosynthesis.

Root activity indicates the metabolic status of whole root system, and affects physiological state of above-ground plant traits (Parys et al., 1998). In order to analysize the effect of G5 strain on decreasing the damage on cucumber seedlings caused by $\mathrm{Cd}$ stress, the root activities of cucumber seedlings were measured after G5 strain treatment. The result showed that $\mathrm{Cd}$ stress reduced root activity of cucumber seedlings compared to the control plant $(P<0.05)$ (Table 2$)$. Root activity showed a decreasing trend as the $\mathrm{Cd}$ concentrations rose and the largest reduction was observed after cucumber seedlings had been treated with $300 \mathrm{mg} \mathrm{L}^{-1} \mathrm{Cd}(63.91 \%$ reduction compared to the control). After treated with G5 strain, the root activities of the seedlings under $\mathrm{Cd}$ stress significantly improved $(P<0.05)$, but by different amounts. G5 strain had the greatest influence on the root activities of cucumber seedlings treated with $300 \mathrm{mg} \mathrm{L}^{-1} \mathrm{Cd}$, which increased by $113.02 \%$ compared to seedlings treated only with $300 \mathrm{mg} \mathrm{L}^{-1} \mathrm{Cd}(P<0.05)$. These results showed that G5 strain treatment increased root activity of cucumber, and further promoted plants for the uptake of nutrients and water.

\section{The effects of G5 strain and Cd treatment on the soluble sugar and soluble protein contents in cucumber seedlings}

Carbohydrates regulate plant growth and enhance plant resistance to stress (Gill et al., 2003). Soluble proteins induce the activities of metabolic enzymes, detoxification enzymes and antioxidant enzymes (Naeem et al., 2011). Under adverse environmental stress, plants often accumulate soluble sugar and soluble protein for reducing their freezing point and osmotic potential, and to activate metabolic enzymes, detoxification enzymes and antioxidant enzymes to help to adapt to the environment (Naeem et al., 2011; Cui et al., 2015). However, when the stress level was overloaded, the soluble sugar and soluble protein contents fell, which impaired plant stress resistance. $50 \mathrm{mg}$ $\mathrm{L}^{-1} \mathrm{Cd}$ stress significantly increased the contents of soluble sugar and soluble protein compared to the control plants $(P<0.05)$ (Table 3). However, the contents of soluble sugar and soluble protein reached the lowest level after $300 \mathrm{mg} \mathrm{L}^{-1} \mathrm{Cd}$ stress $(P<0.05)$ (Table 3$)$. The treatment of G5 strain increased the soluble sugar and soluble protein contents of cucumber seedlings exposed to Cd. G5 strain had the greatest influence on cucumber seedlings treated with $200 \mathrm{mg} \mathrm{L}^{-1} \mathrm{Cd}$ in terms of the soluble sugar contents, and the contents were increased by $57.34 \%$, while G5 strain most improved soluble protein contents of cucumber seedling by $83.73 \%$ when treated with $300 \mathrm{mg} \mathrm{L}^{-1} \mathrm{Cd}$ 
Ge, et al.: Effect of R. palustris $\mathbf{G 5}$ on cucumbe

Table 3: Effects of G5 strain and Cd treatment on the contents of soluble sugar and soluble protein in cucumber seedling

\begin{tabular}{|c|c|c|c|c|}
\hline \multirow[t]{2}{*}{ Concentration (mg L ${ }^{-1} \mathrm{Cd}$ ) } & \multicolumn{2}{|c|}{ Soluble sugar content ( $\left.\mathrm{mg} \mathrm{g}^{-1} \mathrm{FW}\right)$} & \multicolumn{2}{|c|}{ Soluble protein content $\left(\mathrm{mg} \mathrm{g}^{-1} \mathrm{FW}\right)$} \\
\hline & -G5 & +G5 & $-\mathbf{G 5}$ & +G5 \\
\hline 0 & $6.13 \pm 0.01^{b}$ & $8.25 \pm 0.06^{b}$ & $7.25 \pm 0.08^{b}$ & $9.24 \pm 0.11^{b}$ \\
\hline 50 & $7.28 \pm 0.06^{\mathrm{a}}$ & $8.86 \pm 0.03^{a}$ & $8.73 \pm 0.10^{\mathrm{a}}$ & $9.82 \pm 0.29^{a}$ \\
\hline 100 & $5.83 \pm 0.16^{c}$ & $8.10 \pm 0.26^{b}$ & $6.75 \pm 0.04^{b}$ & $8.87 \pm 0.10^{c}$ \\
\hline 150 & $5.21 \pm 0.05^{d}$ & $7.84 \pm 0.05^{c}$ & $5.93 \pm 0.16^{c}$ & $7.73 \pm 0.23^{d}$ \\
\hline 200 & $4.29 \pm 0.45^{\mathrm{ed}}$ & $6.75 \pm 0.04^{d}$ & $4.54 \pm 0.45^{d}$ & $6.18 \pm 0.15^{e}$ \\
\hline 300 & $3.83 \pm 0.7^{e}$ & $5.29 \pm 0.01^{e}$ & $2.95 \pm 0.70^{e}$ & $5.42 \pm 0.24^{\dagger}$ \\
\hline
\end{tabular}

Data are means $\pm \mathrm{SD}$, different lowercase letters in the same column indicate significant differences at $P<0.05$

Table 4: Effects of G5 strain and Cd treatment on antioxidant enzymes and MDA contents in cucumber seedling

\begin{tabular}{|c|c|c|c|c|c|c|}
\hline \multirow[t]{2}{*}{ Concentration (mg L-1 Cd) } & \multicolumn{2}{|c|}{ SOD (U mg-1 Pro) } & \multicolumn{2}{|c|}{ POD (U mg-1 Pro) } & \multicolumn{2}{|c|}{ MDA $\left(\mu \mathrm{mol} \mathrm{g}^{-1}\right.$ Pro) } \\
\hline & -G5 & $+\mathrm{G} 5$ & $-\mathrm{G5}$ & +G5 & $-\mathrm{G5}$ & +G5 \\
\hline 0 & $183.58 \pm 16.47^{b}$ & $226.59 \pm 21.53^{b}$ & $69.58 \pm 1.78^{b}$ & $75.30 \pm 1.62^{c}$ & $39.24 \pm 2.21^{\mathrm{e}}$ & $26.39 \pm 0.90^{\mathrm{e}}$ \\
\hline 50 & $226.49 \pm 30.78^{a}$ & $282.74 \pm 25.64^{a}$ & $90.87 \pm 3.37^{a}$ & $96.7 \pm 2.88^{\mathrm{a}}$ & $46.95 \pm 1.79^{d}$ & $31.32 \pm 5.40^{d}$ \\
\hline 100 & $157.64 \pm 18.68^{b c}$ & $191.28 \pm 18.27^{c}$ & $71.36 \pm 1.06^{b}$ & $88.16 \pm 5.71^{b}$ & $49.73 \pm 1.27^{c d}$ & $35.96 \pm 4.21^{c d}$ \\
\hline 150 & $136.90 \pm 12.83^{\mathrm{cd}}$ & $166.08 \pm 11.80^{\mathrm{cd}}$ & $64.35 \pm 3.31^{c}$ & $71.64 \pm 2.70^{\circ}$ & $53.46 \pm 1.04^{c}$ & $40.64 \pm 3.21^{b c}$ \\
\hline 200 & $111.24 \pm 10.90^{d}$ & $145.59 \pm 9.86^{d}$ & $56.26 \pm 1.29^{d}$ & $72.75 \pm 1.06^{c}$ & $57.53 \pm 3.72^{b}$ & $42.75 \pm 1.68^{b}$ \\
\hline 300 & $68.26 \pm 6.41^{\mathrm{e}}$ & $98.62 \pm 7.06^{e}$ & $43.35 \pm 1.53^{e}$ & $63.38 \pm 1.78^{d}$ & $64.71 \pm 1.58^{\mathrm{a}}$ & $51.64 \pm 1.15^{\mathrm{a}}$ \\
\hline
\end{tabular}

Data are means $\pm \mathrm{SD}$, different lowercase letters in the same column indicate significant differences at $P<0.05$

$(P<0.05)$. After G5 strain treatment, the contents of soluble protein and soluble sugar in the cucumber seedlings increased significantly, suggesting G5 strain treatment improved plant resistance to $\mathrm{Cd}$ stress by increasing the contents of soluble protein and soluble sugar.

The effects of G5 strain and Cd treatment on antioxidant enzyme activities and MDA contents in cucumber seedlings

SOD and POD are the main antioxidant enzyme to scavenge reactive oxygen species (ROS) induced by pollutants and protect cells from damage (Cui et al. 2015). Under biotic and abiotic stress conditions, ROS were produced and then damaged the plant cell. In order to diminish the damage caused by excessive ROS, plants improve stress resistance by enhancing the activities of SOD and POD (Cui et al. 2015). However, when stress exceeded the tolerance threshold of the plant, ROS cannot be eliminated, which results in the decrease in the activities of SOD and POD (Li et al. 2008). Current results showed that increasing in the $\mathrm{Cd}$ concentrations led to improving the SOD and POD activities in the cucumber seedling at first. But these were then followed by decreases in the activities (Table 4). When the Cd concentration was $50 \mathrm{mg}$ $\mathrm{L}^{-1} \mathrm{Cd}$, the activities of SOD and POD in the cucumber seedlings reached to a maximum of $23.37 \%$ and $30.60 \%$, respectively, compared to the control $(P<0.05)$. The G5 strain treatment increased SOD and POD activities of cucumber seedlings under Cd stress. G5 strain most improved the SOD and POD activities of the cucumber seedlings when treated with $300 \mathrm{mg} \mathrm{L}^{-1} \mathrm{Cd}$, and the activities increased by $44.48 \%$ and $46.21 \%$, respectively. This suggested that $G 5$ strain could increase the plant capacity to adapt to stress and alleviate the damage caused by $\mathrm{Cd}$ stress. This findings could be attributed to the fact that G5 strain decreased heavy metal bioavailability in the soil, and produced physiologically active substances, which increase the activities of antioxidant enzyme of plants under stress, enhance plant stress responses, and relieve stress damage to plants (Nunkaew et al., 2014; Xu et al., 2016).

MDA is produced mainly from membrane lipid peroxidation, which means it can be used to assess the degree of membrane lipid peroxidation of plant. Many studies showed that heavy metal stress led to the increasing of ROS, and then caused lipid peroxidation (Mishra et al., 2014; Xu et al., 2008). Current results found that MDA content of cucumber seedling increased with the improving of $\mathrm{Cd}$ concentration $(P<0.05)$ (Table 4$)$. The highest MDA content was observed in seedling treated with $300 \mathrm{mg} \mathrm{L}^{-1}$ Cd stress, which showed a $64.91 \%$ increase compared to the control plants. The increasing of MDA content indicated that the $\mathrm{Cd}$ treatments had led to oxidative stress. However, after treatment with G5 strain, the MDA content of cucumber seedlings among all the treatment fell significantly $(P<0.05)$. G5 strain produced the largest reduction in the MDA content of cucumber seedlings treated with $50 \mathrm{mg} \mathrm{L}^{-1} \mathrm{Cd}$, which decreased by $33.29 \%$ ( $P$ $<0.05)$. In sum, the application of G5 strain alleviated the toxic effects of $\mathrm{Cd}$, and inhibited lipid peroxidation in cucumber seedlings.

\section{CONCLUSION}

The present study demonstrated that G5 strain alleviated the damage of $\mathrm{Cd}$ stress on cucumber seedling, showing 
that G5 strain promoted plant growth, and improved content of soluble protein, soluble sugar and chlorophyll, as well as root activities and activation of antioxidant enzymes, and further led to the diminishing of MDA content in cucumber seedlings exposed to Cd stress. The detoxification mechanism caused by G5 strain under Cd stress is closely connected to the activation of antioxidant enzymes and the accumulation of soluble protein and soluble sugar, which minimizes the oxidative damage induced by Cd stress. Owing to the complexity of the threeway interactions among G5 strain, plant and Cd. Therefore, further studies need to investigate the mechanisms underlying these interactions.

\section{ACKNOWLEDGMENTS}

This study was supported by the Science and Technology Planning Project founded by Science and Technology Commission in Henan Province, China (No. 162102310588) and by the School-based Program of Zhoukou Normal University (No. ZKNUB215210, ZKNUB2201703).

\section{Contributions of authors}

Honglian Ge designed the study. Honglian Ge, Zhonghua Liu and Fuli Zhang performed the experiments and analyzed the data, as well as wrote the paper.

\section{REFERENCES}

Akram, N. A. and M. Ashraf. 2013. Regulation in plant stress tolerance by a potential plant growth regulator, 5-Aminolevulinic acid. J. Plant Growth Regul. 32: 663-679.

Bradford, M. M. 1976. A rapid and sensitive method for the quantitation of microgram quantities of protein utilizing the principle of protein-dye binding. Anal. Biochem. 72: 248-254.

Cui, M. G., Y. C. Lin, Y. G. Zu, T. Efferth, D. W. Li and Z. H. Tang. 2015. Ethylene increases accumulation of compatible solutes and decreases oxidative stress to improve plant tolerance to water stress in Arabidopsis. J. Plant Biol. 58: 193-201.

El-Beltagi, H. S., A. A. Mohamed and M. M. Rashed. 2010. Response of antioxidant enzymes to cadmium stress in leaves and roots of radish (Raphanus sativus L.). Not. Sci. Biol. 2: 76-82.

Fargašová, A. 2001. Phytotoxic effects of $\mathrm{Cd}, \mathrm{Zn}, \mathrm{Pb}, \mathrm{Cu}$ and $\mathrm{Fe}$ on Sinapis alba L. seedlings and their accumulation in roots and shoots. Biol. Plant. 44: 471-473.

Gill, P. K., A. D. Sharma, P. Singh and S. S. Bhullar. 2003. Changes in germination, growth and soluble sugar contents of Sorghum bicolor (L.) moench seeds under various abiotic stresses. Plant Growth Regul. 40: 157-162.

Gill, S. S and N. Tuteja. 2011. Cadmium stress tolerance in crop plants: Probing the role of sulfur. Plant Signal Behav. 6: 215-222.

Hegedüs, A., S. Erdei and G. Horváth. 2001. Comparative studies of $\mathrm{H} 2 \mathrm{O} 2$ detoxifying enzymes in green and greening barley seedlings under cadmium stress. Plant Sci. 160: 1085-1093.

Horváth, G., M. Droppa, Á. Oravecz, V. L. Raskin and J. B. Marder.
1996. Formation of the photosynthetic apparatus during greening of cadmium-poisoned barley leaves. Planta. 199: 238-243.

Hotta, Y., T. Tanaka, H. Takaoka, Y. Takeuchi and M. Konnai. 1997. Promotive effects of 5-aminolevulinic acid on the yield of several crops. Plant Growth Regul. 22: 109-114.

Kerley, S. J. 2000. The effect of soil liming on shoot development, root growth, and cluster root activity of white lupin. Biol. Fertil. Soils. 32: 94-101.

Li, S., S. Zhang, X. Ding, X. Liao and R. Wang. 2013. Spraying silicon and/or cerium sols favorably mediated enhancement of $\mathrm{Cd} / \mathrm{Pb}$ tolerance in lettuce grown in combined $\mathrm{Cd} / \mathrm{Pb}$ contaminated soil. Procedia Environ. Sci. 18: 68-77.

Li, Y., Q. Zhou, F. Li, X. Liu and Y. Luo. 2008. Effects of tetrabromobisphenol a as an emerging pollutant on wheat (Triticum aestivum) at biochemical levels. Chemosphere. 74: 119-124.

Lutts, S., J. M. Kinet and J. Bouharmont. 1996. NaCl-induced senescence in leaves of rice (Oryza sativa L.) cultivars differing in salinity resistance. Ann. Bot. 78: 389-398.

Mishra, B., R. S. Sangwan, S. Mishra, J. S. Jadaun, F. Sabir and N. S. Sangwan. 2014. Effect of cadmium stress on inductive enzymatic and nonenzymatic responses of ROS and sugar metabolism in multiple shoot cultures of ashwagandha (Withania somnifera Dunal). Protoplasma. 251: 1031-1045.

Naeem, M. S., M. Rasheed, D. Liu, Z. L. Jin, D. F. Ming, K. Yoneyama, Y. Takeuchi and W. J. Zhou. 2011. 5-aminolevulinic acid ameliorates salinity-induced metabolic, water-related and biochemical changes in Brassica napus L. Acta. Physiol. Plant. 33: $517-528$.

Nunkaew, T., D. Kantachote, H. Kanzaki, T. Nitoda and R. J. Ritchie. 2014. Effects of 5-aminolevulinic acid (ALA)containing supernatants from selected Rhodopseudomonas palustris strains on rice growth under $\mathrm{NaCl}$ stress, with mediating effects on chlorophyll, photosynthetic electron transport and antioxidative enzymes. Electron. J. Biotechnol. 17: $19-26$.

Parys, E., E. Romanowska, M. Siedlecka and J. W. Poskuta. 1998. The effect of lead on photosynthesis and respiration in detached leaves and in mesophyll protoplasts of Pisum sativum. Acta. Physiol. Plant. 20: 313-322.

Popova, L. P., L. T. Maslenkova, R. Y. Yordanova, A. P. Lvanova, A. P. Krantev, G. Szalai and T. Janda. 2009. Exogenous treatment with salicylic acid attenuates cadmium toxicity in pea seedling. Plant Physiol. Bioch. 47: 224-231.

Pružinská, A., G. Tanner, I. Anders, M. Roca and S. Hörtensteiner. 2003. Chlorophyll breakdown: Pheophorbide a oxygenase is a rieske-type iron-sulfur protein, encoded by the accelerated cell death 1 gene. PNAS. 100: 15259-15264.

Sasaki, K., M. Watanabe, Y. Suda, A. Ishizuka and N. Noparatnaraporn. 2005. Applications of photosynthetic bacteria for medical fields. J. Biosci. Bioeng. 100: 481-488.

Xu, J., Y. Feng, Y. Wang, X. Luo, J. Tang and X. Lin. 2016. The foliar spray of Rhodopseudomonas palustris grown under Stevia residue extract promotes plant growth via changing soil microbial community. J. Soils Sediments. 16: 916-923.

Xu, P., J. Zou, Q. Meng, J. Zou, W. Jiang and D. Liu. 2008. Effect of $\mathrm{Cd}^{2+}$ on seedling growth of garlic (Allium sativum L.) and selected physiological and biochemical characters. Bioresour. Technol. 99: 6372-6378.

Wang, M. E. and Q. X. Zhou. 2006. Joint stress of chlorimuron-ethyl and cadmium on wheat Triticum aestivum at biochemical levels. Environ. Pollut. 144: 572-580. 
Weckx, J. E. J. and H. M. M. Clijsters. 1996. Oxidative damage and defense mechanisms in primary leaves of Phaseolus vulgaris as a result of root assimilation of toxic amounts of copper. Physiol. Plant. 96: 506-512.

Wu, Y. X. and A. von Tiedemann. 2002. Impact of fungicides on active oxygen species and antioxidant enzymes in spring barley (Hordeum vulgare L.) exposed to ozone. Environ. Pollut. 116: 37-47.

Zarco-Tejada, P. J., A. Berjón, R. López-Lozano, J. R. Miller, P. Martín, V. Cachorro, M. R. González and A. de Frutos. 2005. Assessing vineyard condition with hyperspectral indices: Leaf and canopy reflectance simulation in a row-structured discontinuous canopy. Remote Sens. Environ. 99: 271-287. 